\title{
Climate Adaptation Research for the Next Generation
}

\begin{abstract}
The last decade has seen a rapid proliferation of climate change adaptation research resulting in a broad theoretical and conceptual understanding of adaptation. However, significant gaps still exist in applying these theoretical frameworks and tools in policy and practice. There is also little agreement on which methods and frameworks are truly robust, while many developing countries lack access to key literature and data. Several issues are especially relevant for early career researchers and practitioners. These include working in an area of science that crosses disciplinary boundaries, improving the quality of and capacity to undertake adaptation research, and equity and ethics. We elaborate on these themes based on our experiences as early career adaptation researchers working in developed and developing countries. We also identify several support mechanisms required to enable early career researchers to advance their engagement with the climate change adaptation agenda.
\end{abstract}

\section{Introduction}

Research on climate change adaptation has matured rapidly over the past decade. This knowledge base provides a theoretical foundation for what adaptation means and how it could be implemented successfully in different contexts (Adger et al., 2005, Adger et al., 2007, Burton et al., 2002, Füssel and Klein, 2006, Smit et al., 1999, Smit and Wandel, 2006). Despite these conceptual and theoretical advancements in adaptation research (Smit et al., 2000) the actual process of adaptation remains messy and confusing in its conceptualisation and practical application (Adger and Barnett, 2009). Several researchers have recently stressed the need for closer integration of adaptation theory and practice, which if left unchallenged is likely to constrain the outcomes for communities and end-users (Eakin and Patt, 2011, Pathawardhan et al., 2009, Preston and Stafford-Smith, 2009).

Traditionally, to address issues of environmental change, scientists begin their careers by studying and specialising in a specific discipline (e.g. geography, anthropology, ecology) and it is with these disciplinary backgrounds that their skills and knowledge have been transferred and applied recently to examining contemporary issues such as climate change adaptation. However, as many early career researchers now step directly into "climate change adaptation" as a standalone and emerging discipline, several challenges and opportunities have emerged. Here, we discuss some of these disjunctions and emerging prospects with a particular focus on early career researchers who are navigating through the ever-increasing field of "adaptation science".

Our discussion draws on the literature and our personal experiences as early career researchers in Australia, Guatemala, Mexico, South Africa, the Netherlands, and the Pacific, each of us having contributed to a panel session at the Adaptation Futures conference held at the University of Arizona in May 2012. While we do not claim to 
be the first to note these challenges, we see however little discussion of their implications for current adaptation research and practice.

\section{The Disciplinary Challenge}

The recent expansion of the climate change adaptation research field has allowed scientists from diverse disciplines to engage in a wide range of projects. However, the development of adaptation research into its own scholarly community has received criticism prompting some scholars to suggest that adaptation simply represents a new form of environmental determinism (O’Brien, 2012). For example, Schipper (2007) notes that divorcing adaptation from the broader development agenda and research context reduces our ability to provide useful additional knowledge relevant to development under a changing climate. Dovers and Hezri (2010) criticise adaptation research for becoming a self-referencing, inward looking entity with the potential to overlook important contributions from other disciplines. For early career researchers engaged in adaptation research, this "disciplinary challenge" represents a particularly significant constraint. The most valuable adaptation research is multidisciplinary (Agrawal et al., 2012); this places an additional requirement on early career researchers to engage across a broad range of disciplines relevant to adaptation. Deciding on which disciplines are relevant for addressing specific research questions, and perhaps more importantly which disciplines may be irrelevant, is somewhat of a disciplinary maze. This particularly impacts early career researchers who may have limited exposure or experience in working across the social, natural and human sciences.

Although experienced researchers may find this framing unhelpful and unnecessary, for many early career researchers this poses a dilemma. How much knowledge specific to adaptation does one need in order to contribute to the field and what should the balance be? Should early career researchers adopt a climate change adaptation lens through which to examine, for example, current urban planning frameworks, or conversely study urban planning and design, prior to considering climate change adaptation frameworks and concepts? In practice these approaches may be adopted simultaneously but deciding on the starting point in this multidisciplinary field remains a challenge. Should adaptation be pursued by the development of new approaches and the formation of new institutions (Hallegatte, 2009) or should it be 'normalised' and integrated into existing frameworks (Dovers, 2009)?

Across the adaptation research community and especially in developing countries where research institutions are in their infancy, we have an opportunity to remove the barriers associated with single-discipline focussed learning environments. From undergraduate courses to postdoctoral research, the formation of multidisciplinary research groups and teaching institutions will help to produce a new type of scientist who is more capable and confident to work across traditional disciplinary boundaries. A number of early career researchers already benefit from such multidisciplinary environments but it is increasingly important to build skills and abilities in multidisciplinary working to effectively tool the next generation of adaptation researchers. 
A first challenge to overcome in the development of multidisciplinary research environments is to refine a common theoretical language. Concepts central to adaptation research such as 'adaptation', 'adaptive capacity', 'vulnerability', 'sensitivity', 'resilience', 'effectiveness' and 'transformations' have different connotations and applications across different disciplines and stakeholder groups (Füssel and Klein, 2006, Preston and Stafford-Smith, 2009, Smit and Wandel, 2006, Wolf, 2012). One method to address this challenge would be the development of coherent and systematic guidance of common definitions, their theoretical underpinnings, their distinct uses and the various approaches adopted in studying for example, adaptation, vulnerability, transformations, adaptive capacity and environmental change.

Instead of a one-size-fits-all approach, it would be helpful to develop comprehensive guidance on how these concepts are applied in different contexts (e.g. disaster risk reduction versus adaptive water management) and what common lessons might be extracted from their application. A bibliography and synthesis of key papers would especially help to guide younger researchers. This guidance should be in an open access format allowing researchers and practitioners from less well-resourced institutions and countries to benefit equally. Recent initiatives addressing this include the newly formed PROVIA under UNEP, whose guidance book on Vulnerability, Impacts and Adaptation (VIA) is currently under review and the UNEP sourcebook (under development) on how to teach climate change adaptation at university level in developing countries. The utility of these guidance materials depends, naturally, on their dissemination, uptake and relevance for policy and practice.

\section{Improving quality and capacity}

International funding for adaptation is increasing rapidly (Donner et al., 2011) bringing a profound need to ensure that adaptation research and practice promotes reflexivity and strives to continuously improve in quality. Currently, a dearth of information and limited human and institutional capacity within many developing nations means that the quality of adaptation research and practice is not assured. The situation is improving slowly, with the recognition by the international community to improve climate services capabilities in developing nations (Boulahya, 2010; Hewitt et al., 2012), but increased investment in capacity building within developing nations is clearly needed. For example, in Mexico opportunities for adaptation research and policy are already changing due to regulatory mandates and increased investment (CICC, 2012a/b, Diario Oficial de la Federación, 2012). The national General Law on Climate Change for instance mandates all state and municipal authorities to develop and implement climate change adaptation programmes.

A particular risk that we observe affecting the 'quality' of adaptation research and practice occurs where new investment and funding opportunities encourage actors without sound experience or knowledge of the field to claim expertise. For example, over the last five years, the Pacific Island Countries (PICs) have increasingly become drenched in climate adaptation funds. Many PICs often do not possess the internal capacity to make scholarly or technical contributions and manage formal climate adaptation programmes. This has attracted a wide range of external practitioners and researchers to fill this capacity deficit as climate adaptation specialists. Although they may possess years of experience in international development or other specialist 
disciplines, many have a limited understanding of the theoretical underpinnings of adaptation or the use of multidisciplinary approaches to addressing adaptation. Early career researchers might often lack 'formal' work experience in planning programs and projects but can be well rehearsed in multidisciplinary approaches and adaptation theory. As monitoring and evaluation (M\&E) methods for adaptation are still in their nascent stages (Eakin and Patt, 2011, Preston et al., 2010), an opportunity exists for early career researchers to apply these theoretical understandings to challenge conventional development-based M\&E methods. Focusing on in-country capacity and knowledge building could contribute more to national actors' self-determination and capability to make informed decisions (Clark, 2009).

Currently a large number of 'lessons learned' are currently being lost due to the reporting structures and peer-review process where it is not popular to report on the challenges and difficulties faced in the research process. Some reporting has reviewed the underlying assumptions of particular approaches such as vulnerability assessments (see Füssel and Klein, 2006, Preston et al., 2011) or climate change risk assessments (Ekström et al., 2012), but information is missing on the practical context where constraints and opportunities are experienced at first hand. Very few papers have raised the need to examine potential conceptual confusion regarding core concepts (Klein, 2009), critique of dominant narratives (Patt, 2012) or report on practical obstacles when using methodologies and analysis regarding VIA assessments. For example, while evidence suggests that adaptation projects are more successful if they involve a high level of participation and stakeholder engagement (Conde and Lonsdale, 2005, Steynor et al., 2012), very few report on the complexities and difficulties in stakeholder engagement processes that clearly impact on the process and subsequent identification of adaptation priorities and strategies. Stock taking and cataloguing the most robust and successful approaches and tools and when and how they are applied in particular contexts would ensure coherent guidance resulting in useful typologies that match method and context.

\section{Embedding equity and ethics in adaptation research practice}

Besides the identified constraints associated with single disciplinary research environments and the varied conceptual language of adaptation, an additional significant but somewhat tractable constraint is the translation of research output into the native language of researchers and, perhaps more importantly, the vulnerable communities. For early career researchers in non-English speaking countries, this challenge is real and should not be dismissed. Adaptation guidance and research findings should not be confined to a single language (predominantly English); indeed the need for adaptation is often higher in more vulnerable countries/communities where English is not necessarily spoken. By producing outputs in local languages where necessary, a major obstacle to the uptake and awareness of best-practice adaptation could be reduced. This could also promote sustainable adaptation and give those who are adapting a greater voice in the process (Eriksen et al., 2011). Early career researchers, who are often encouraged to study and report in English, have a responsibility to ensure this issue is addressed within their institutions now and in the future.

Approaches to adaptation are largely context dependent and more often than not require local capacity to enact solutions. Given that the most severe impacts of 
climate change are expected to occur in the poorest nations and communities primarily in the Global South (Stern, 2007), greater emphasis is needed on sustained efforts to build and invest in local capacity where it is currently lacking (Mustelin et al., 2010). Co-authorship of papers between international and national researchers and practitioners should be common practice and not a 'kind' occasional gesture. 'Intergenerational' forums could bring together early career researchers from developing countries and adaptation experts from various countries to collectively engage in unpacking adaptation related research challenges. Emphasis on where and by whom adaptation projects are designed needs to be examined as projects designed to aid communities in Asia, Africa and Latin America funded, designed and coordinated predominantly in Europe, North America and Australasia.

Acknowledging the value of Indigenous knowledge, increasing local stakeholders' involvement in project design and coordination, and truthfully accounting for the environmental impact of travel between continents implores the next generation of adaptation researchers to think differently about their role in developing sustainable adaptation solutions.

\section{Conclusions}

Climate change adaptation research is an essential component in enabling society to respond in a changing world. However, the burgeoning of climate change adaptation research, increasingly referred to as "adaptation science", has produced a set of emerging challenges that particularly affect early career researchers and practitioners. Here, we have outlined several key challenges and potential opportunities to strengthen the field and support available. Given the theoretical maturity of the field, there is a need to test the robustness of existing assumptions and practices embedded in adaptation research. Adaptation science challenges our conventional disciplinary approaches and in order to enable a new generation of adaptation scientists to advance their contributions to solving tomorrow's problems, we need to focus on expanding the support they need.

\section{Acknowledgments}

The authors would like to thank Professor Diana Liverman for supporting the Arizona panel, Professor Richard Klein and the two anonymous reviewers for their constructive comments. Any shortcomings remain our sole responsibility.

\section{References}

Adger, N.W., Arnell, N. W., Tompkins, E.L., 2005, 'Successful adaptation to climate change across scales', Global Environmental Change Part A, 15, 77-86.

Adger, N. W., Agrawala, S., Mirza, M. M. Q, Conde, C., O’Brien, K., Pulhin, J., Pulwarty, R., Smit, B., Takahashi, K., 2007, 'Assessment of adaptation practices, options, constraints and capacity’, In: Parry, M. L., Canziani, O.F., Palutikof, J.P., Van Der Linden, P. J., Hanson, C.E. (eds) Climate Change 2007: Impacts, Adaptation and Vulnerability. Contribution of Working Group II to the Fourth Assessment Report of the Intergovernmental Panel on Climate Change. Cambridge: Cambridge University Press. 
Adger, W. N., Barnett, J., 2009, 'Four reasons for concern about adaptation to climate change', Environment and Planning A 41(12), 2800-2805.

Agrwawal, A., Lemos, M.C., Orlove, B., Ribot, J., 2012, 'Cool heads for a hot world: Social sciences in the changing sky', Global Environmental Change 22, 329-331.

Boulahya, M. S., 2010, 'Climate services for development in Africa', in: A. Troccoli (ed), Management of Weather and Climate Risk in the Energy Industry, Proceedings of the NATO Advanced Research Workshop on Weather/Climate Risk Management for the Energy Sector, Santa Maria di Leuca, Italy, 6-10 October 2008, Springer, 89104.

Burton, I., Huq, S., Lim, B., Pilifosova, O., Schipper, E. L., 2002, 'From impacts assessment to adaptation priorities: the shaping of adaptation policy', Climate Policy 2(2-3), 145-159.

Clark, D. A., 2009, 'Adaptation, poverty and well-being: Some issues and observations with special reference to the capability approach and development studies', Journal of Human Development and Capabilities 10(1), 21-42.

Comisión Intersecretarial de Cambio Climático (CICC), 2012a, 'Adaptación al cambio climático en México: visión, elementos y criterios para la toma de decisiones', INECC, Ciudad de México, México.

CICC, 2012b, 'Informe de avances del Programa Especial de Cambio Climático 2009-2012', SEMARNAT, Ciudad de México, México.

Conde, C., Lonsdale, K., 2005, 'Engaging stakeholders in the adaptation process', in: Lim, B., Spanger-Siegfried, E., Burton, I., Malone, E. L., Huq, S. (eds.), Adaptation policy frameworks for climate change: developing strategies, policies, and measures, Cambridge, UK; New York: Cambridge University Press, 47-66.

Diario Oficial de la Federación, 2012, 'Ley General de Cambio Climático', $6^{\text {th }}$ of June 2012, DOF, Ciudad de México, México.

Donner, S. D., Kandlikar, M., Zerriffi, H., 2011, 'Preparing to manage climate financing', Science 334, 908-909.

Dovers, S., 2009, 'Normalizing adaptation', Global Environmental Change 19, 4-6.

Dovers, S. R., Hezri, A. A., 2010, 'Institutions and policy processes: the means to the ends of adaptation', Wiley Interdisciplinary Reviews: Climate Change 1, 212-231.

Eakin, H. C., Patt, A., 2011, 'Are adaptation studies effective, and what can enhance their practical impact?', Wiley Interdisciplinary Reviews: Climate Change 2, 141-153.

Eriksen, S., Aldunce, P., Bahinipati, C. S., Martins, R. D. A., Molefe, J. I., Nhemachena, C., O'Brien, K., Olorunfemi, F., Park, J., Sygna, L., Ulsrud, K., 2011, 'When not every response to climate change is a good one: Identifying principles for sustainable adaptation', Climate and Development 3, 7-20. 
Ekström, M., Kuruppu, N., Wilby, R., Fowler, H.J., Chiew, F.H.S., Dessai, S., Young W.J., 2013, 'Examination of climate risk using a modified uncertainty matrix framework-Applications in the water sector', Global Environmental Change 23, 115-129.

Füssel, H.-M., Klein, R., 2006, 'Climate Change Vulnerability Assessments: An Evolution of Conceptual Thinking', Climatic Change 75(3), 301-329.

Hallegatte, S., 2009, 'Strategies to adapt to an uncertain climate change', Global Environmental Change 19, 240-247.

Hewitt, C., Mason, S, Walland, D., 2012, 'The global framework for climate services', Nature Climate Change 2, 831-832.

Klein, R., 2009, 'Identifying countries that are particularly vulnerable to the adverse effects of climate change: An academic or a political challenge?', Carbon and Climate Law Review 3, 284-291.

Mustelin, J., Klein, R., Assaid, B., Sitari, T., Khamis, M., Mzee, A., Haji, T., 2010, 'Understanding current and future vulnerability in coastal settings: community perceptions and preferences for adaptation in Zanzibar, Tanzania', Population \& Environment 31(5), 371-398.

O'Brien, K., 2012, 'Global environmental change II: From adaptation to deliberate transformation', Progress in Human Geography 36(5), 667-676.

Patt, A., 2012, 'Multi-level climate adaptation policy and causation narratives', Geografisk Tidsskrift-Danish Journal of Geography, 112(2), 174-182.

Patwardhan, A., Downing, T., Leary, N., Wilbanks, T., 2009, 'Towards an integrated agenda for adaptation research: theory, practice and policy: Strategy paper', Current Opinion in Environmental Sustainability 1, 219-225.

Preston, B., Stafford-Smith, M., 2009, 'Framing vulnerability and adaptive capacity assessment: Discussion paper', CSIRO Climate Adaptation National Research Flagship, Working Paper 2. Available at http://www.csiro.au/org/ClimateAdaptationFlagship.html, accessed 8.10.2010.

Preston, B., Westaway, R., Yuen, E., 2010, 'Climate adaptation planning in practice: an evaluation of adaptation plans from three developed nations', Mitigation and Adaptation Strategies for Global Change, 1-32.

Preston, B., Yuen, E., Westaway, R., 2011, 'Putting vulnerability to climate change on the map: a review of approaches, benefits, and risks'. Sustainability Science, 1-26.

Schipper, E. L. F., 2007, 'Climate Change Adaptation and Development: Exploring the Linkages'. Tyndall Centre for Climate Change Research Working Paper 107, July 2007, http://www.preventionweb.net/files/7782_twp107.pdf. accessed 7.2.201. 
Smit, B., Burton, I., Klein, R. J. T., Street, R., 1999, 'The Science of Adaptation: A Framework for Assessment', Mitigation and Adaptation Strategies for Global Change 4(3), 199-213.

Smith, B., Burton, I., Klein, R. J. T., Wandel, J., 2000, 'An Anatomy of Adaptation to Climate Change and Variability', Climatic Change 45, 223-251.

Smit, B., Wandel, J., 2006, 'Adaptation, adaptive capacity and vulnerability'. Global Environmental Change 16, 282-292.

Steynor, A., Gawith, M., Street, R., 2012, 'Engaging users in the development and delivery of climate projections: the UKCIP experience of UKCP09', UK Climate Impacts Programme, Oxford, UK.

Stern, N., 2007, 'The Economics of Climate Change: the Stern Review', Cambridge University Press, Cambridge, UK.

Wolf, S., 2012, 'Vulnerability and risk: comparing assessment approaches', Natural Hazards 61(3), 1099-1113. 